\title{
GLOBAL STIFFNESS ANALYSIS OF BIW STRUCTURE
}

\author{
Sharanbasappa ${ }^{1}$, E Sujith Prasd ${ }^{2}$, Praveen Math ${ }^{3}$ \\ ${ }^{I}$ PG Student, Master of Technology in Machine Design, Mechanical Engineering Department, T John Institute of \\ Technology, Bangalore, Karnataka, India \\ ${ }^{2}$ Professor \& HOD, Mechanical Engineering Department, $T$ John Institute of Technology, Bangalore, Karnataka \\ ${ }^{3}$ Professor \& HOD, Mechanical Engineering Department, T John Institute of Technology, Bangalore, Karnataka
}

\begin{abstract}
This paper mainly involves the global stiffness analysis of entire Body In White (BIW) structure of car that includes the torsional stiffness, sag analysis under appropriate load cases and boundary conditions it suits the real loading conditions. The purpose of this analysis is to check the stiffness (strength) of BIW structure as it takes up the entire vehicle self-weight along with the occupant's weight under consideration. If the BIW structure does not have sufficient stiffness it will produce unnecessary deformations under different loading conditions when put into operation, it also effect the dynamic performance \& ride comfort $t$ of vehicle hence it is necessary to provide proper stiffness to the BIW structure of vehicle under consideration. Sedan is considered as the car variant, skeleton analysis is taken for the work, in which the number of load is acting on the car body but we are considering the Bending \& Torsional load for the calculation purposes.
\end{abstract}

Keywords: BIW: Body in White $* * *$

\section{INTRODUCTION}

Global stiffness analysis is carried out to check the overall stiffness of the vehicle, since the stiffness is very important parameter for vehicle design and it is important for meeting NVH targets and light weight targets, higher the stiffness higher will be the weight and less vibration absorbing capacity of the vehicle on the other end if stiffness values are too less (lower stiffness) then strength will be lower which is not acceptable, hence optimal stiffness is essential for better performance of vehicle in terms of taking up vibrations while running condition also to take self- weight.

\section{CONSTRUCTION OF SKELETON MODEL}

This body structure consist of number of several parts but in this project work body is considered as closed section type member and open section of panels, these are represented by a $1 \mathrm{D}$ beam element by doing this the size of the vehicle can reduced in comparison to finally meshed modal this meshed part has done by using the shell element. From the other side if we expressed the structure as a beam element in BIW model there may highlight some problems around the joint of vehicle, where elements are interconnected.

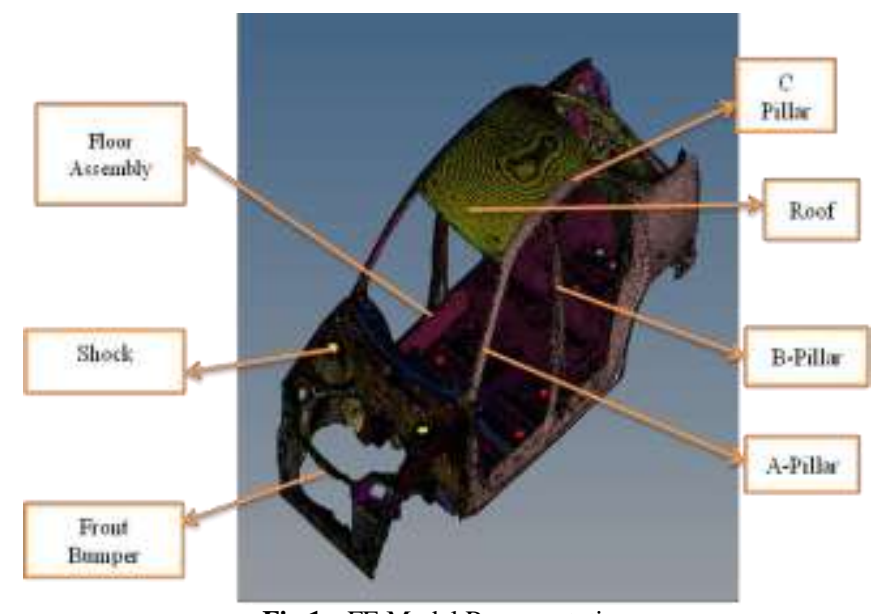

Fig 1:- FE Model Representation

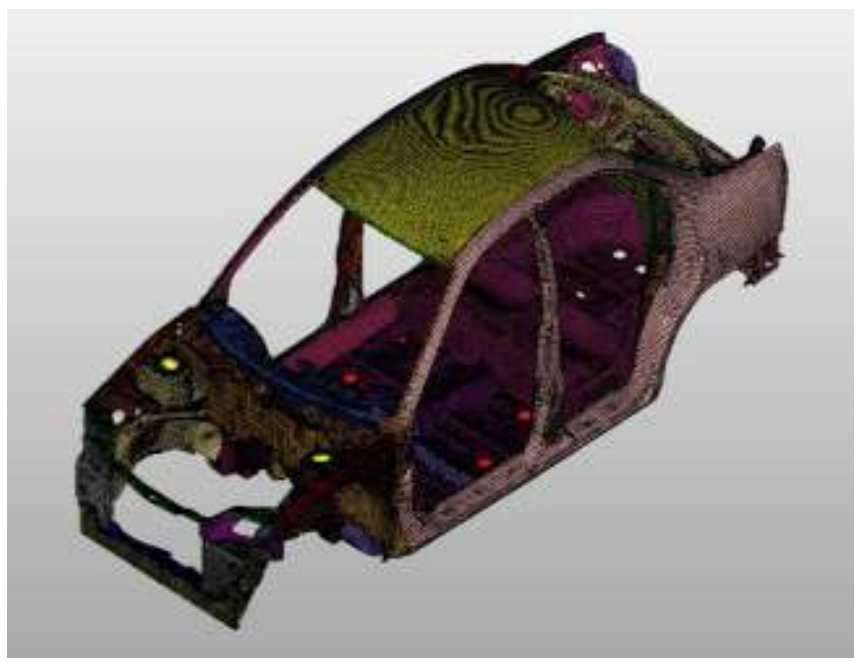

Fig 2:- Real Structure and Skeleton Model 


\subsection{Stiffness for Bending (Bending stiffness)}

There is a more than one method to determine the stiffness of bending and their properties, which are force of bending and moment of bending, because they can fulfill a meaning of bending stiffness. That is evaluating bending stiffness methods are the resonance bending stiffness method. In this work the load is applied at four point to check bending stiffness also we have the another method to calculate the bending stiffness is two point method in which the load will acted at only two points, in this work can also calculate for two point but we are more concentrated on four point bending stiffness method. When we cannot measure bending stiffness at some point but we can correlate with bending stiffness by using some available data. The all obtained result always reported inthe form of resistance bending.

\subsection{Torsion}

In the area of mechanics of solids two equal and opposite couples acting about the axis of shaft gives rise to torsion. The unit of torsion is $\mathrm{KN}-\mathrm{m}$ or $\mathrm{N}-\mathrm{m}$ etc. Power is generally transmitted from motor to compressor, turbine to generator; motor to pump etc.

The angle of twist can be defined as the angle of twist in a shaft is the angle through which the section at the right side end rotates about the longitudinal axis and angle of twist is measured with reference to the section at the top side end or bottom side end of the shock tower .in which also the torsional strength is defined as the torque per unit maximum shear stress. Torsional shaft is also known as the efficiency of a shaft. Also torsional rigidity is defined as it is the torque required to produce a unit angle of twist in a specified length of the shaft. Torsion for a uniform cross section of a shaft is given by:

$T=\frac{J_{T}}{r} \tau=\frac{J_{T}}{\ell} G \theta$

\subsection{Stiffness}

Basically the stiffness is given by the ratio of applied force or force acting on a body to the displacement caused by the force. The stiffness is symbolically represented by the $\mathrm{k}$.

$k=\frac{F^{r}}{\delta}$

Where, F - Force applied in N.

$\delta$ - Displacement in $\mathrm{mm}$.

According to International System of standards, stiffness istypically calculated in newton per meter.

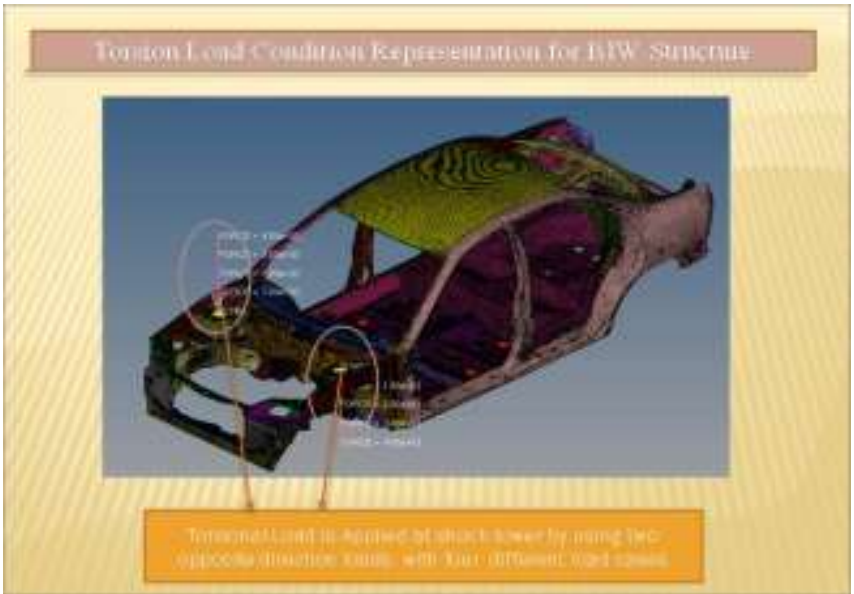

Fig 3:- Torsion Load Condition Representation for BIW Structure

Torsional Load is applied at shock tower by using two opposite direction loads with four different load cases in front shock tower and aldegree of freedom are arrested at back case.

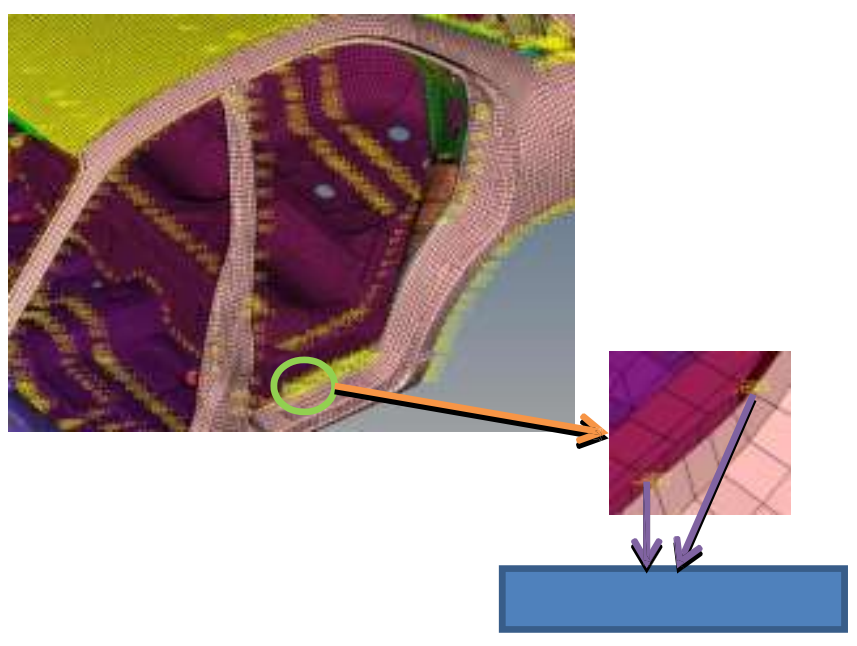

Fig 4:- Spot weld Representation

\section{METHODOLOGY}

\subsection{Finite Element Modeling (Pre-Processing)}

FE Modelling is done in HYPERMESH V12 software since itis dedicated software for complete preprocessing activity such as meshing of complex geometry, material properties assigning, sectional properties assigning \&applying boundary conditions etc. can done with greater ease.

\subsection{Analysis of BIW Structure By Using Static} Method

Torsional and bending loads are implemented according to the Hyundai motor company test specifications and procedure. The displacement will commonly measure in both tests for applied load by using dialgauge and measured deflections, in which mainly torsional rigidity and static bending stiffness have been calculated at different places for different load cases, the boundary conditions and applied loads are shown in skeleton model. 
$[\mathrm{K}][\mathrm{U}] 1=[\mathrm{F}] 2$

Where

[K] - stiffness matrix. [U] 1 - displacement. [F] 2 - force applied.

\subsection{Analysis of Static Bending Boundary Conditions}

For the boundary condition the loads applied at the seat to check the bending stiffness in which the stiffness will change due to change in load because of that we considered $1000 \mathrm{~N}$ load for the bending condition because there is no chance to apply the more than $1000 \mathrm{~N}$ in passenger vehicle for thus we assumed also which does not effect to the efficiency also which is holds good for the material property. In this work the bending stiffness is important for the model design, even the spot welding is not affected but we gave little importance to spot welding. Also, boundary conditions are declared that rotation $\mathrm{y}$ is free and remaining 5 DOF are arrested at back shock tower. Details are shown in the figure 3.2.

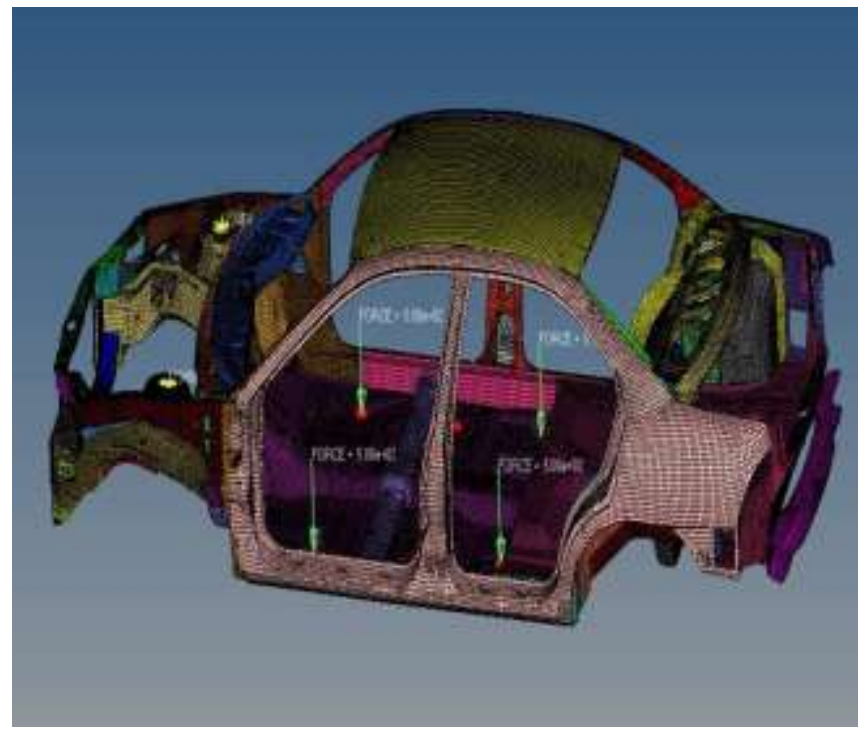

Fig.5 Boundary Conditions

\subsection{Static Torsion Analysis Boundary Conditions}

We applied load on ashock tower for a different load condition first applied for $1000 \mathrm{~N}$ we obtained the result but not satisfied again hanged the load for $2000 \mathrm{~N}$ not found the required result for $3000 \mathrm{~N}$ also was not good but for the load $4000 \mathrm{~N}$ we obtained the worst result but this satisfied the required result. According to industries level, so we satisfied the result for $4000 \mathrm{~N}$ the applied load conditions are shown in fig 3.4

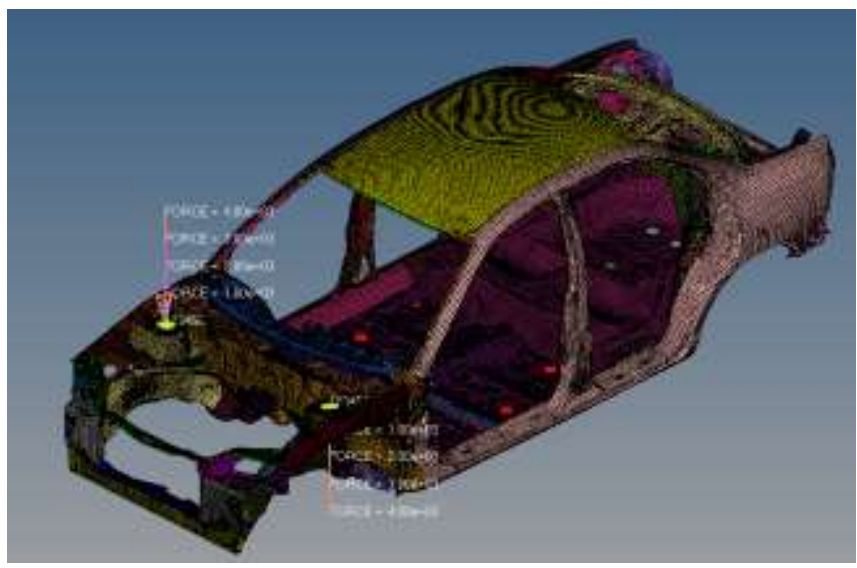

Fig.6 Torsion Load Condition

\section{RESULTS}

In this project we calculate the bending stiffness as well as torsional stiffness for that we will calculate the deflection fora bending and angle of twist for a torsional from the analysis. Itis a function of elastic modulus, the area moment of inertia of the beam cross section about the axis of interest, length of the beam and beam boundary condition. And in case of bending the deflection for lateral bending stiffness is $0.02200 \mathrm{~mm}$ for both conditions we applied force obtained value of maximum deflection for vertical bending stiffness is $0.006500 \mathrm{~mm}$ and maximum is 1000.00

N.

As we know the basic bending stiffness formula

$B s=\frac{F}{\delta}$

Where,

Bs - Bending stiffness in N/mm. F- Applied force in N.

$\delta$-Deflection in $\mathrm{mm}$. In which we calculate the bending stiffness in two cases

\section{Vertical bending stiffness}

For vertical bending stiffness

$B s v=\frac{F v}{\delta}$

Where,

Bsv - Vertical bending stiffness in N/mm. Fv - vertically applied force in $\mathrm{N}$.

$>$ Lateral bending stiffness

For Lateral bending stiffness 
$B s l=\frac{F l}{\delta}$

Where,

Bsl - Lateral Bendingstiffness in N/mm.

$\mathrm{F}_{1}-$ Lateral applied force in $\mathrm{N}$.

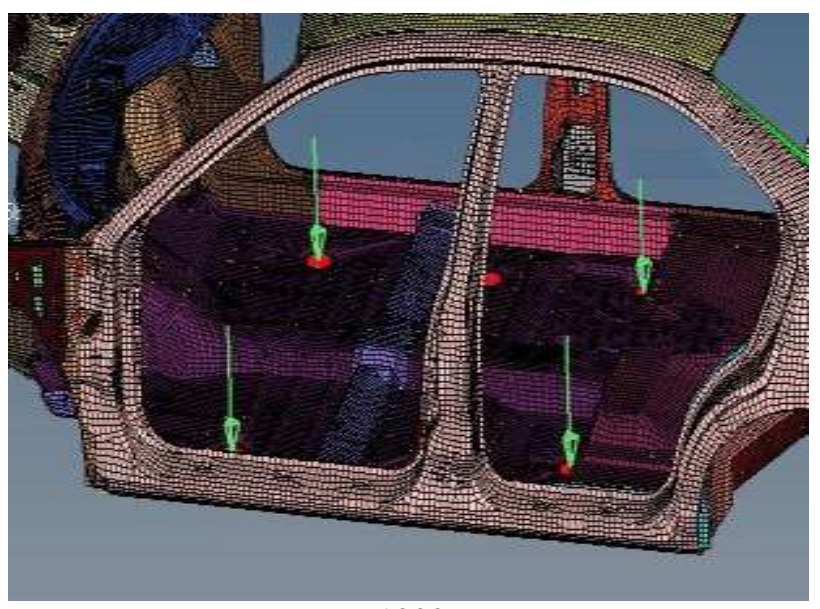

$\mathrm{F}=1000 \mathrm{~N}$

Fig.7 Load applied in Bending Condition for 1000N

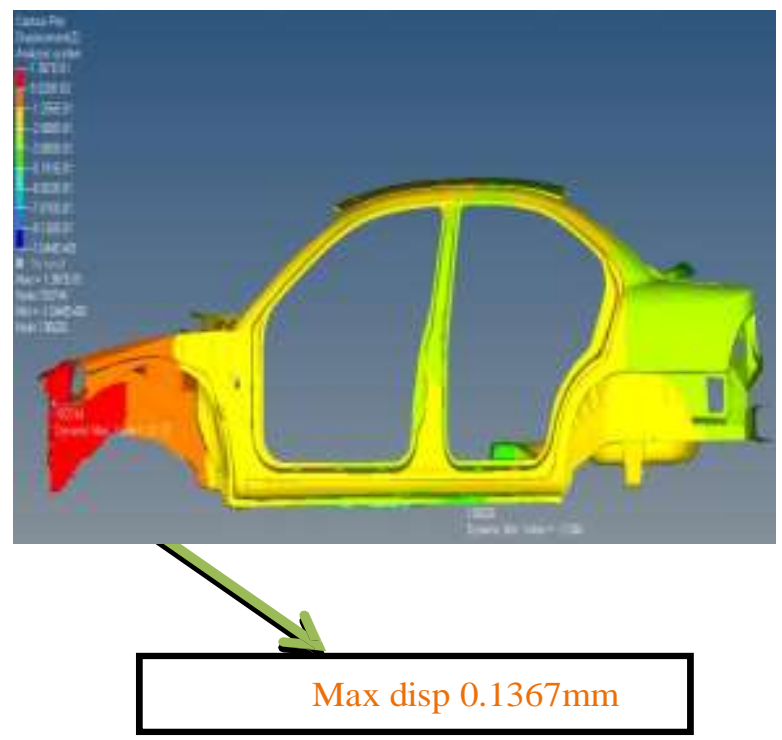

Fig.8 Displacement plots for Bending load 1000N

\section{CALCULATION}

Bending stiffness for vertical

$$
\begin{aligned}
& B s v=\frac{F v}{\delta} \\
& B s v=\frac{1000}{0.0065} \\
& B s v=153846.153 \mathrm{~N} / \mathrm{mm}
\end{aligned}
$$

Bending stiffness for lateral

$$
\begin{aligned}
& B s l=\frac{F l}{\delta} \\
& B s l=\frac{1000}{0.022} \\
& B s l=45454.545 \mathrm{~N} / \mathrm{mm}
\end{aligned}
$$

Calculation of bending stiffness for maximum displacement

$$
\begin{aligned}
B s d & =\frac{F d}{\delta} \\
B s d & =\frac{1000}{0.1367} \\
B s d & =7315.2899 \mathrm{~N} / \mathrm{mm}
\end{aligned}
$$

For validation purpose we need to check the value of analysis FEA that is as we know another formula for calculating the stiffness is given by

$K=\frac{48 E I}{L^{3}}$

Where

K-stiffness in $\mathrm{N} / \mathrm{mm}$

E-young's modulus of material in $\mathrm{N} / \mathrm{mm} 2$

I-Moment of inertia in $\mathrm{mm} 4$

L-length of model in mm

The value of young's modulus is taken from the design data hand book $\mathrm{E}=200 \mathrm{GPa}$, moment of inertia is taken from the FEA result that is shown in following snaps and stiffness value is calculated by using above formula.

\section{CALCULATION}

$K=\frac{48 E I}{L^{3}}$

$K=\frac{48 * 200 * 10^{9} * 74.68}{2500^{3}}$

\section{$K=45883.392 \mathrm{~N} / \mathrm{mm}$}

Percentage of error is given by

$\%$ of error $=\frac{\text { maximum value }- \text { minmum value }}{\text { maximu value }}$

$\%$ of error $=\frac{45883.392-45454.545}{45883.392} * 100$

$\%$ of error $=\mathbf{0 . 9 3 4 6} \%$ 


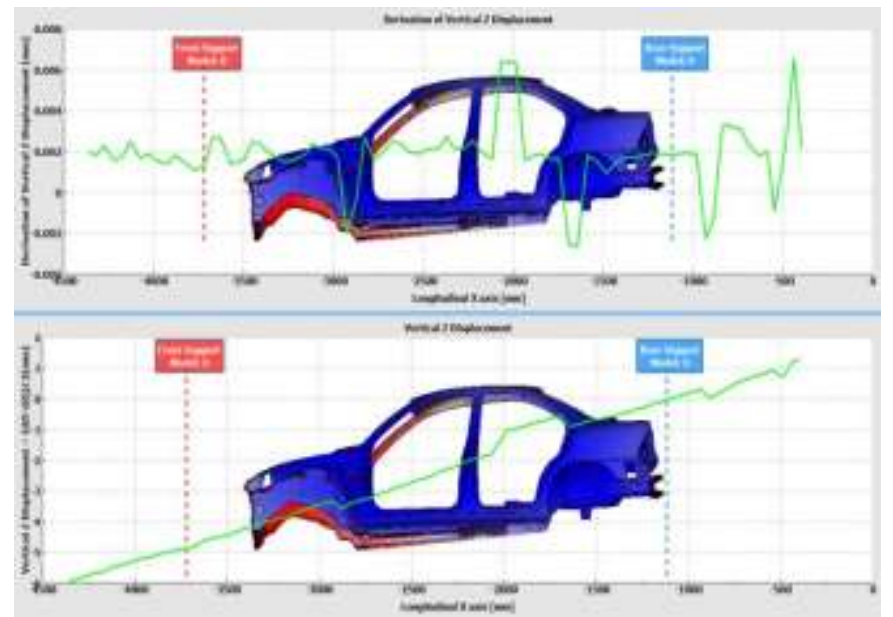

Fig.9 Bending Vertical deflection v/s longitudinal $\mathrm{X}$ axis length plot

Above plot shows the variation of bending deflection (vertical) along the length of BIW structure, from this data we can calculate bending stiffness by using the relation, $\mathrm{B} s=(\mathrm{F} / \delta), \quad \mathrm{B} s=\mathrm{Bending}$ Stiffness, $\mathrm{F}=$ Applied Force, $\delta=$ Bending deflection.

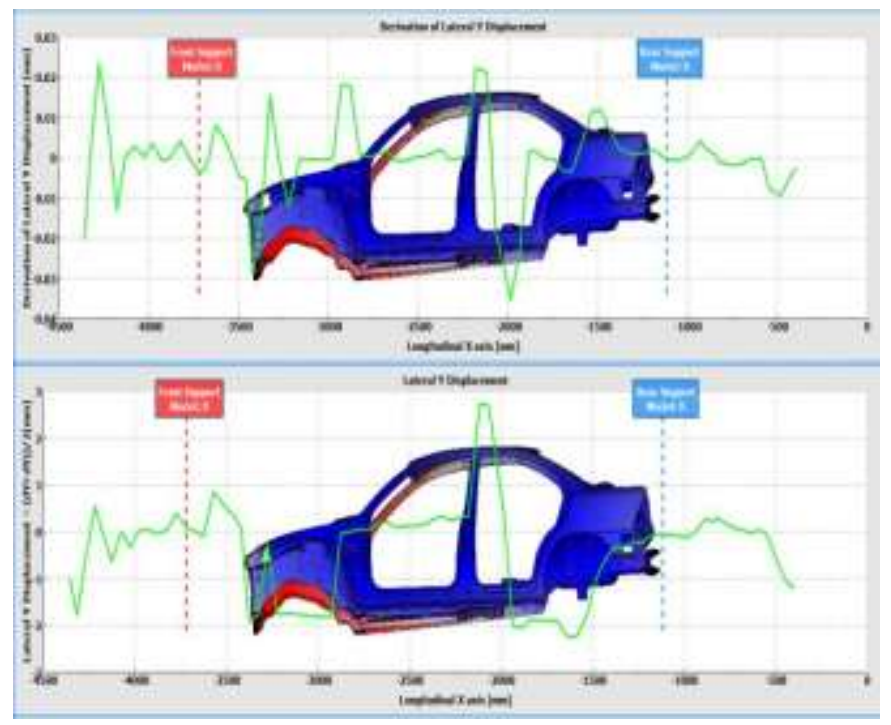

Fig.10 Bending lateral deflection v/s longitudinal $\mathrm{X}$ axis length plot

Comparison of Theoretical and Analysis for

\section{Bending Stiffness}

\begin{tabular}{|c|c|c|c|}
\hline $\begin{array}{c}\text { Types of } \\
\text { Bending }\end{array}$ & $\begin{array}{c}\text { Theoretical } \\
\text { Result } \\
(\mathrm{N} / \mathrm{mm})\end{array}$ & FE $(\mathrm{N} / \mathrm{mm})$ & $\begin{array}{c}\text { \% of } \\
\text { Error }\end{array}$ \\
\hline $\begin{array}{c}\text { Vertical } \\
\text { Bending } \\
\text { Stiffness }\end{array}$ & 45883.3920 & 153846.1530 & 70.00 \\
\hline $\begin{array}{c}\text { Lateral } \\
\text { Bending } \\
\text { Stiffnes }\end{array}$ & 45883.3920 & 45454.5450 & 0.93460 \\
\hline $\begin{array}{c}\text { Stiffness due } \\
\text { to maxi } \\
\text { displacement }\end{array}$ & 45883.3920 & 7315.28990 & 84.050 \\
\hline
\end{tabular}

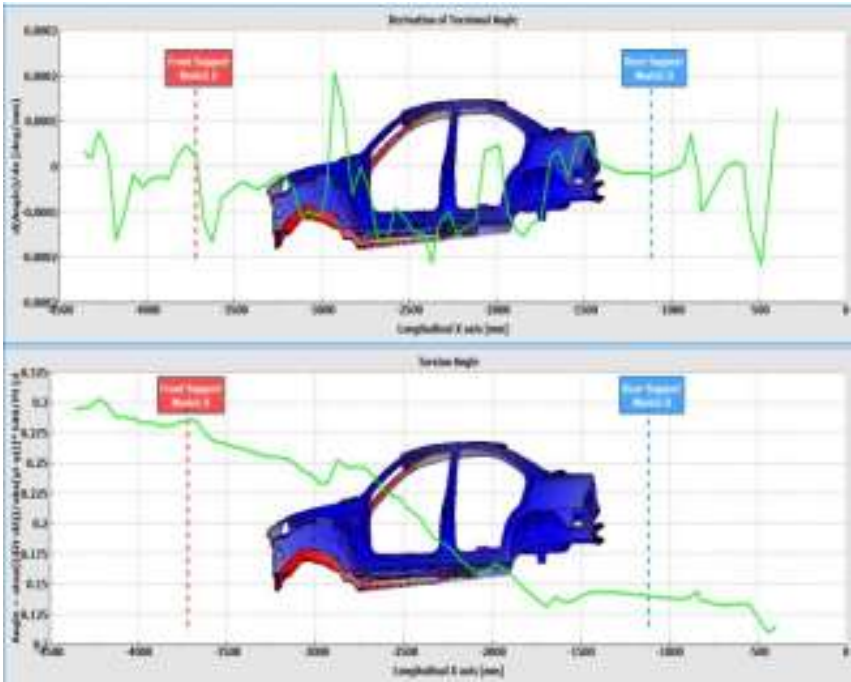

Fig.11. Torsional Angle v/s longitudinal X axis length plot

Above plot shows the variation of torsional Angle along the length of BIW structure, from this data we can calculate torsional stiffness by using the relation, Ts $=(\mathrm{T} / \Theta)$, Ts =Torsional Stiffness, $\mathrm{T}=$ Applied Torque, $\Theta=$ Angle of twist (torsional angle).

In torsional stiffness condition we obtain the value for maximum angle of twist is 0.2500 and the external applied force is $4000.00 \mathrm{~N}$ so according to above equestion the torsional stiffness is given by $\mathrm{TS}=\frac{T}{\theta}$

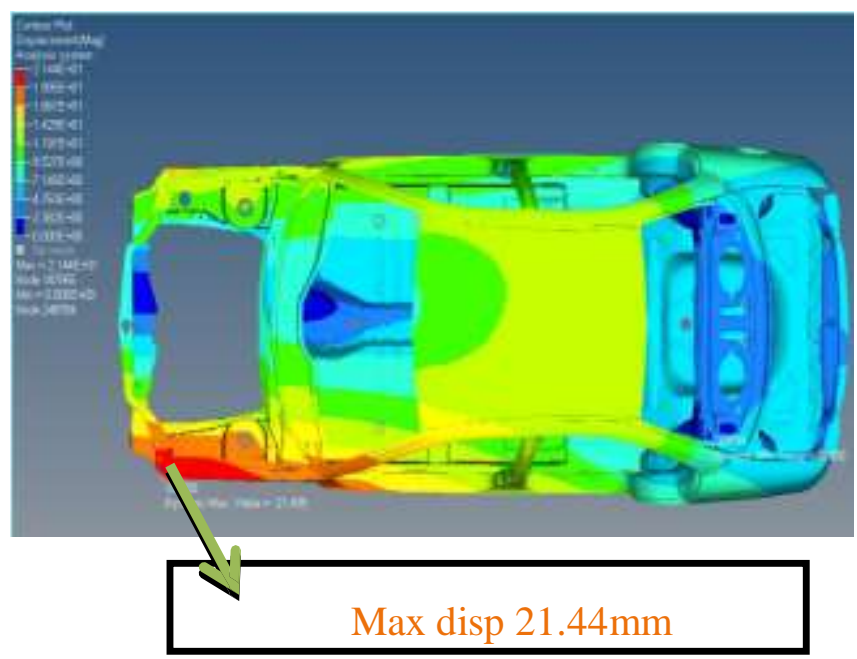

Fig.12. Stress plots for torsional load 4000N-m

From work

$\mathrm{T}=4000.00 \mathrm{~N},{ }^{\theta}=0.2500$

Therefore $\mathrm{TS}=\frac{T}{\theta}=\frac{4000}{0.25}$

$\mathrm{TS}=16000[\mathrm{Nm} / \mathrm{deg}]$

$\mathrm{TS}=16.00 \quad[\mathrm{KNm} / \mathrm{deg}]$ 


\section{Comparison of Theoretical And Analysis for}

\section{Torsional Stiffness}

\begin{tabular}{|l|l|c|l|}
\hline $\begin{array}{l}\text { Types of } \\
\text { Stiffness }\end{array}$ & $\begin{array}{l}\text { Theoretical } \\
\text { Result } \\
{[\mathrm{KNm} / \mathrm{deg}]}\end{array}$ & FE $[\mathrm{kNm} / \mathrm{deg}]$ & $\begin{array}{l}\% \text { of } \\
\text { Error }\end{array}$ \\
\hline $\begin{array}{l}\text { Torsional } \\
\text { Stiffness }\end{array}$ & 16.00 & 14.65134603 & 8.4290 \\
\hline
\end{tabular}

\section{CONCLUSSION}

Lateral bending stiffness and torsional stiffness are acceptable values whereas vertical bending stiffnes sand maximum displacement due to vertical loading are verifying with respect to theoretical results because of complicated geometry. Majorly vertical bending stiffness compared by torsional stiffness calculation in FEA so its ignorable.

\section{REFERENCES}

[1] Young-woo lee, "Skelton model for the body structure of a passenger car" Volume 1, Issue 1, December 1996, Pages 426-428

[2] Red jers, Yang, Juneja "dynamic and static stiffness analysis of one test, and both results". December 1960, Ml 48083

[3] J. Helsens 1,L. Cremer 2 ,P. Mas 3 , P. Sass 1 "Global static and dynamic of car body structure stiffness based on a single experimental modal analysis method march 1973, pages 501-503

[4] Nicholas Lutsey, "Review of technical literature and trends relates the automobile mass- reduction technology" Californian Air Resource Board - May 2010, pages 410-413

[5] Steven Tebbyy1, Ebrahimm Esmailzadehh 2 \& Ahmad Barari 3 "Determining Methods of Torsion Stiffness in an Automotive Chassis FEA, automotive, structure". DOI:

[6] 10.3722/cadaps.2011.pages.67-75

[7] Supriya Burgul, "literature review for analysis, design, and fatigue life of a mechanical spring of car" vol. 2 issue.7, July 2014. pages: 76-83

[8] Karthikeyan S. A (1), Pavendan R (2) "design \& analysis of chassis for 2214 truck" e-issn: 22781684, p-issn: 2320-334x, pages. 26-33

[9] K. Michalczyk, "literature review for analysis, design, and fatigue life of a mechanical spring of car" volume. 2 issue.7, July 2014. pages: 76-83

[10] Pravin A Renuke "dynamic analysis of a car chassis" volume. 2, Issue 6, November- December

[11] 2012, pages.955-959 